\title{
The Covid-19 vs Globe : Turn Disaster Into Opportunity
}

\author{
Dr. Ranjana Kanungo ${ }^{1}$, Deepak K. Nama ${ }^{2}$
}

${ }^{1}$ Christian Eminent College, Devi Ahilya Vishwavidyalaya, Indore, Madhya Pradesh, India

${ }^{2}$ Department of Commerce, Devi Ahilya Vishwavidyalaya, Indore, Madhya Pradesh, India

\section{ABSTRACT}

\section{Article Info}

Volume 8, Issue 3

Page Number : $70-81$

\section{Publication Issue}

May-June-2021

\section{Article History}

Accepted : 01 May 2021

Published : 05 May 2021
In the megatrend of the novel coronavirus (COVID-19), we need to react this pandemic with positive vibe, with making another world, which brimming with lots of creativity, respectability, imagination, development and not with stagnation. We attempt to figure out how human being transforms challenges into opportunities and get returns under financial recession. In this paper, we prescience the open doors for a superior world that this destructive emergency brings to us. We review the various destruction caused by this epidemic and major emphasis review on the opportunities which lie underneath the epidemic like: visible opportunities that have been implemented during the breakout and the concealed opportunities which will go ahead and become part of our business strategy. In the end, we made conclusions and recommendations for our stocks.

Keywords : Coronavirus (COVID-19); Destruction; Visible Opportunities; Concealed Opportunities; Outbreak Crisis; Risk Mitigation.

\section{INTRODUCTION}

A fad never brings a change because its life is short while a trend is more predictable then fashion, maybe it brings a difference, but when a long-lasting effect happens on us, A megatrend comes into the environment. The megatrend is a "significant social, economic, political, and technological change where the whole globe faces the megatrend of novel coronavirus (COVID-19). Kamradt-Scott, A., \& Lee, K. (2011).

It's been roughly a month now since the Coronavirus started to flip our lives upside down. For the first weeks of COVID-19, it felt like the end of the world was finally here. The stock market was falling; companies were laying people off, people were forced to work from home, grocery shelves emptied, and almost every country in the world had infections and deaths soaring - there seemed to be no end in sight. Atkeson, A. (2020).

A pandemic is defined as the "worldwide spread of a new disease." The spread of novel coronavirus, SARSCoV-2, was officially defined as a pandemic by the World Health Organization (WHO) on March 11, 2020, due to its sudden emergence and expansion around the world.On December 31, 2019, the WHO China Country Office was informed of cases of pneumonia unknown etiology (unknown cause) 
detected in Wuhan City, Hubei Province of China. From December 31, 2019, through January 3, 2020, a total of 44 case-patients with pneumonia of unknown etiology reported to $\mathrm{WHO}$ by the national authorities in China. During this reported period, the causal agent was not identified.On 12 January 2020, WHO received further detailed information from the National Health Commission China that the outbreak is associated with exposures in one seafood market in Wuhan City. The Chinese authorities identified a new type of coronavirus, which was isolated on 7 January 2020.A third of the world's population is living under lockdown regulations because of the coronavirus pandemic. Measures vary from country to country; for example, China only implemented lockdowns in some of its cities, whereas Italy has forced its population to stay indefinitely within the home. WHO (2020). A country based on the movement of capital, labour, services, manufacturing, production, import-export, etc. has been stable. The whole flow of the economy has been restricted.

The new coronavirus is turning out to be a considerable pressure test for globalization. As essential flexibly anchors break, and countries crowd clinical supplies and hurry to constrain travel, the emergency is compelling a significant re-examination of the interconnected worldwide economy. Not just has globalization took into consideration the fast spread of infectious ailment. Yet, it has encouraged profound association among firms and countries that make them increasingly powerless against startling stuns. Presently, firms, furthermore, countries the same are finding exactly how helpless they are. Henry Farrell and Abraham Newman(2020). We aim in this paper to think beyond the curve; the principle venture reasoning is concentrating on the businesses that to be profited the most during this crisis period. Identification of destruction and explore the changes that come to light by this coronavirus (covid-19). The paper is organized as follows: follows. Relevant previous researches are reviewed in Section 2. In
Section 3, methodology. In section 4, result finally in section 5 , discussion and conclusion.

\section{LITERATURE REVIEW}

\subsection{Outbreak period: destruction}

2.1.1 How does the infection connected influence the economy?

Pierre-Olivier Gourinchas answers this question elegantly in his chapter: "A modern economy is a complex web of interconnected parties: employees, firms, suppliers, consumers, banks and financial intermediaries. Everyone is someone else's employee, customer, lender, etc." If one of these buyer-seller links is ruptured by the disease or containment policies, the outcome will be a cascading chain of disruptions.

Figure 1. COVID19's multiple strikes in the circular flow of income

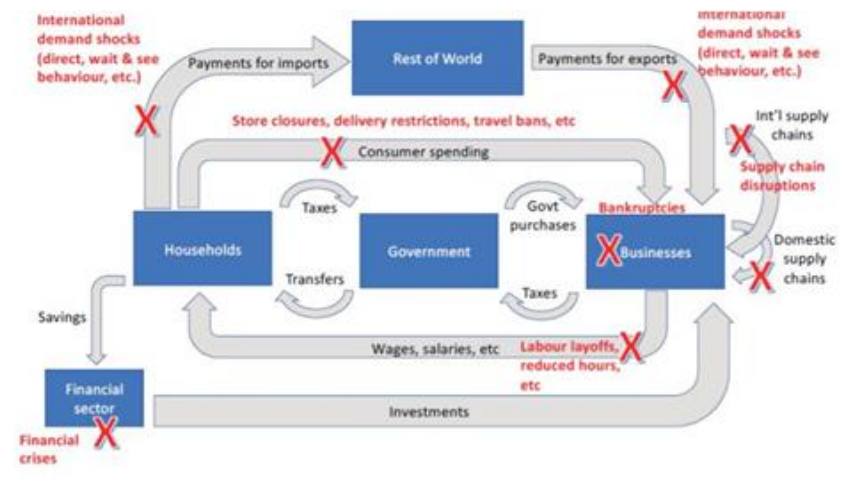

Based on Baldwin (2020)

Above figure shows the COVID19's multiple strikes in the circular flow of income diagram. The diagram is an adaptation of the notable round cash stream outline that is found in generally basic economic textbooks. In simplified form, households own capital and labour, which they sell to businesses, who use it to make things that families then buy with the money businesses gave them, thereby completing the circuit and keeping the economy growing. In short, a stream disruption anyplace causes a stoppage all over the place.The red crosses show were the three types of shocks are disrupting the economy. Starting 
from the far left and moving clockwise, we see households who don't get paid experience financial distress and slow their spending. Second, the domestic demand shocks hit the nation's imports and thus the flow of money to foreigners. While this doesn't reduce domestic demand directly, it does mitigate foreign incomes and, therefore, their spending on the nation's exports (the cross in the top-right corner). The reduction in order and direct supply shocks can lead to a disruption in international and domestic supply chains (the two crosses on the right). Both lead to a further reduction in output, especially in the manufacturing sectors. The hit to manufacturing can be exaggerated by the wait-and-see behavior of people and firms. Manufacturing is especially vulnerable since many manufactured goods are postpone-able (the cross in the bottom-right corner).Baldwin (2020).

\subsubsection{The Global shares take a hit}

The FTSE, Dow Jones Industrial Average and the Nikkei have all seen huge falls since the outbreak began on 31 December.

Figure 2. The Impact of Coronavirus on stock markets since the start of $t$ outbreak

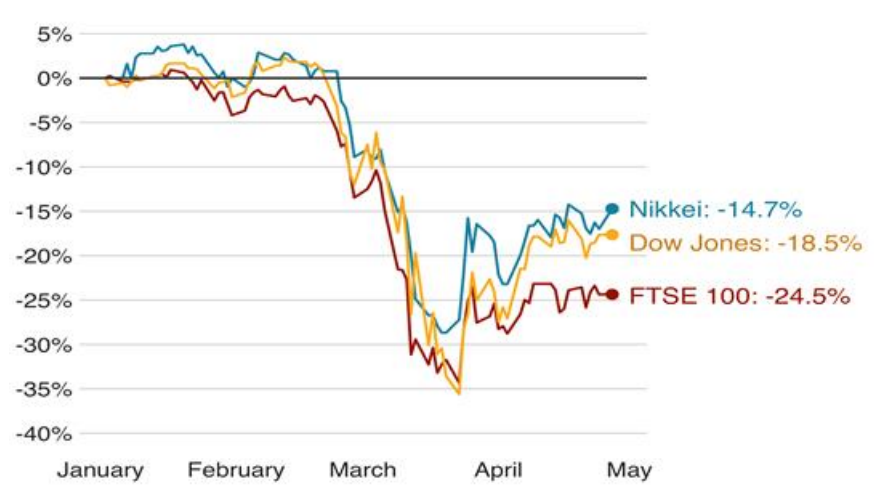

Bloomberg (April, 27, 2020)

covid-19 influences the people's safety as well as the budgetary market. For model, the pandemic has made the US financial exchange trigger the circuit breakers four times in March, 2020. The colossal ailment related decrease in the financial exchange could in this manner cause the speculators to endure heaps of riches misfortune and make the financial specialists' mentality toward the future economy progressively critical. Cheng, H. P., \& Yen, K. C. (2020).

\subsubsection{More people seeking work}

In the United States, the number of people filing for unemployment hit a record high, signaling an end to a decade of expansion for one of the world's largest economies.

\section{Figure 2 more than 30million people in the US have \\ filed for unemployment benefits in last six weeks.}

Weekly total of new unemployment claims in 2020

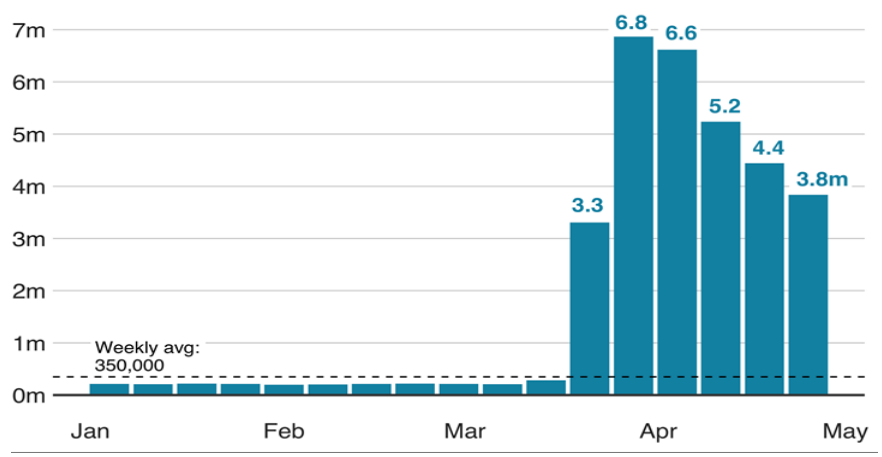

US Bureau of Labor Statistics (April 30)

The appearance of the covid-19 infection and the arrangement reactions have prompted uncommon quantities of introductory cases for joblessness since mid 2020: over 16.5 million by April fourth, 2020, with new cases showing up at a pace of 6-7 million every week. Be that as it may, worries about express governments' failure to process such a significant number of cases in such a brief period, joined with the way that numerous laborers are ineligible for joblessness benefits, has prompted worries that all out work misfortunes are being downplayed by these numbers. Coibion (2020)

\subsubsection{Oil prices crash}

Demand for oil has all but dried up as lockdowns across the world have kept people inside.The unrefined petroleum cost had just been influenced by a column between OPEC, the gathering of oil makers, and Russia. 
Figure 3 Oil Price at 21-year low

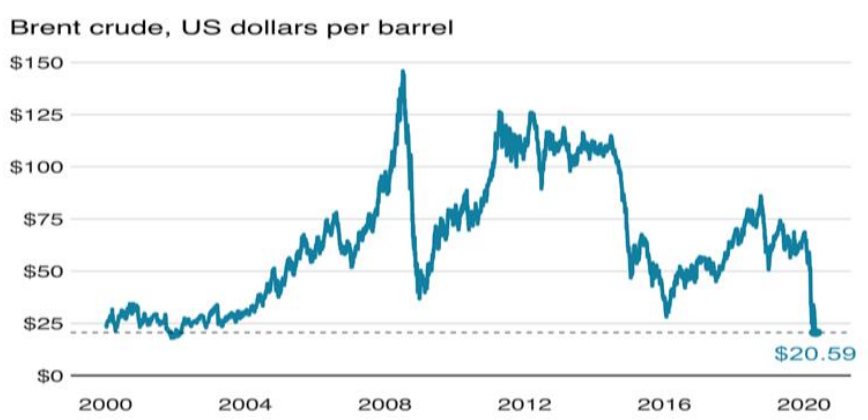

Bloomberg (April, 27, 2020)

The new coronavirus has created important stun waves on budgetary markets, yet additionally on commodity prices, including oil. Oil costs recorded the hardest cut after 1991, which help, for the moment, the economy of oil-bringing in nations seriously influenced by the coronavirus emergency. Nonetheless, the accident of oil costs plainly shows that a monetary downturn can't be maintained a strategic distance from. . Albulescu, C. (2020).

\subsubsection{Risk of recession}

If the economy is developing, that, for the most part, implies more riches and all the more new openings. It's deliberate by taking a gander at the rate change in total national output, or the estimation of products and enterprises created, regularly more than a quarter of a year or a year. In any case, the International Monetary Fund (IMF) says that the worldwide economy will shrivel by $3 \%$ this year.

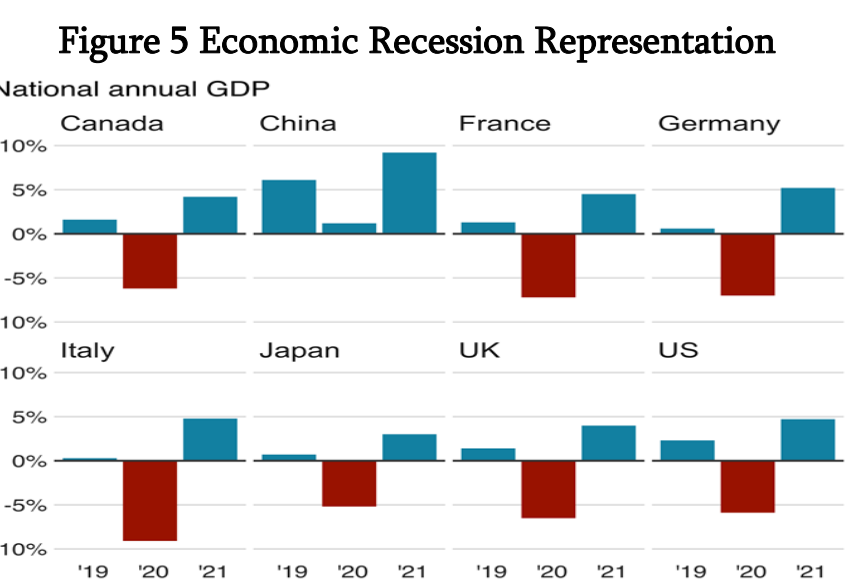

\section{International Monetary Fund (IMF)}

There is no uncertainty that financial markets now attribute significant troublesome potential to Covid19 , and those dangers are genuine. In any case, the varieties in resource valuations underline the significant vulnerability encompassing this pandemic, and history alerts us against drawing a straight line between financial showcase sell-offs and the genuine economy. . Carlsson-Szlezak (2020)

\section{2 breakout: Visible Opportunities}

\subsubsection{Well-being Driven Entrepreneurial Opportunities after Coronavirus}

Coronavirus disturbance has demonstrated that we are in phase with new innovative activities. These creative ventures centre around opening the ability to contact individuals electronically and accommodate them esteem included administrations that decrease their dread and upgrade their likelihood of confronting perils securely. Buheji (2019a).Studies show that, in total, there would be more than 97 million Chinese voyagings abroad by 2023 , with an estimated yearly development pace of over 5.0\% throughout the following ten-year, Oxford Economics (2015). In this manner, the use of security-driven worth included administrations could give exceptional qualities to the purchasers that alleviate the dangers of unexpected life dangers.

2.2.2. New Point of view for Changing the Way We See Life Today

With the emergency of coronavirus breakout, we could find numerous apparent chances. One of the first open doors is to reconsider the ideas that are commanding our life today, for example, the capitalist economy and its assets and how delicate they are. Here we see the biggest worldwide savings, for example, China and Italy, crumbling before coronavirus. Kim and Liu (2012). Therefore, coronavirus can represent a chance to review how we should live in harmony in this world and keep the communication model between us without extra unnecessary boundaries. The (COVID-19) emergency is a reminder for the individuals who esteem the personal satisfaction and the individuals who respect 
money related premiums paying little heed to the results to worldwide wellbeing or people. These degrees of qualities were seen obviously in a portion of the carriers' business, which expanded the people's cross-contamination dangers, after knowing the risks of such infection. The National Academies of Sciences

\section{Engineering Medicine (2016a).}

\subsubsection{Self Sufficient Synergetic Human Communities}

The other noticeable change (COVID-19) challenge brings is that it made us give more consideration to the significance of independence and preparation or expanded readiness. This triggers more change in the work instruments and to discover feasible components that help to revise our inside life and how it is developed. The collaboration of people was additionally more evident in this (COVID-19), which help the pressures of many enraptured regions regardless of the progressing wars in numerous nations. Network solidarity that such profound, complex emergency would bring to the brain of the innumerable the quintessence of being and living respectively in this world. Green (2011)

\subsubsection{Exploiting our Intrinsic Power}

The other principle opportunity that (COVID-19) emergency is that it would make us progressively mindful about the 'inherent forces' we have inside us, which are a higher priority than different assets, including other common assets. This suggests those with low degrees of self-control would be more needing mental guides. Li, J. B., Yang (2020)

\subsubsection{Greater Credibility and Transparency in} Relevance to Common Global Issue

One of the advantages of the stuns of this emergency is that it drove the bar further up for the interest for better validity and straightforwardness in issues applicable to the essential globe. The detailing and revelation of (COVID-19) ailment became a network right, yet gone further to be a human right clearly, and the emergency would acquire increasingly creative advancements in significance to clinical and social insurance prerequisites and administrations. In any case, progressively significant the world would be likewise increasingly mindful of the concealed foe that we as a whole need to battle together paying little heed to our disparities and level of decent varieties. Bogoch, I. I., Watts (2020)

\subsection{Breakout: concealed opportunities}

The coronavirus emergency indicated that the world is so delicate and non-flexible, yet besides the world is brimming with concealed possibilities and unfamiliar changes. Since there are new difficulties that accompany the intricacies of this destructive infection without a doubt, we have to search for the concealed opportunities that could support our intensity in the current and the future foresighted environment. Buheji(2020a).Concealed opportunities, as a rule, rely upon the states of seriousness when an emergency ejects. For example, how we could deal with the coming recession as a result of such a crisis, including managing the socio-economic complications as result of such crisis. Hidden opportunities, once discovered, can help close the 'competitiveness gap' and ensure better international and regional sustainable (socialeconomic \& environmental) growth. This means the opportunities would come from the global 'diverging socio-economic development' and the 'unbalanced growth models'. Thus, the hidden opportunities might come from the collection of approaches that brings in chronic human issues like migration, rising non-resilience racial tensions, loss of acceptance of others, future foresight spillovers affect, fragile businesses with preventive measures, e-solutions, speed of innovation along with international communication possibilities. Helmich, R. C., \& Bloem, B. R. (2020)

2.3.1. Coronavirus as a Multi-disciplinary ProblemSolving Challenge

After this awful phenomenon, we may presumably develop a culture that lives with experimentation. No 
more ages that would look disappointment of examinations as a disgrace, yet the genuine humiliation would be not testing to be prepared for such an emergency as (COVID-19) and would encourage more prominent information. Holmes, $\mathrm{K}$. V. (2003)

(COVID-19) the crisis brought the need of solving complex problems by a holistic multi-disciplinary approach. The breakout needed investigation, diagnosis and treatments that used medical, technological, legal, managerial, philosophical, psychological, sociological, economical, besides historical approaches. All these multi-disciplinary approaches used communication models and were applied within the organizations, the communities and the globe. Buheji(2018).

\subsubsection{Reexamining the Business Models}

The occurrence of Coronavirus gives us time to rethink about the business models we adopted in our life. The significance of the generosity esteem in our business model ought to be one of the exercises learned. Government, organizations and communities could re-evaluate the good corporate governance (ethical and the transparency) issues of different industries, i.e. doing and creating businesses from things that you don't own. It is an excellent opportunity for people, organizations and communities or countries to come out of the safe or comfort zone. Here we can assemble new relations as we see the world after the crown challenge from an alternate point of view, because of the mentalities and social changes that are brought about by our past suspicion stun. The new changes in the manners we handle many schedules in life give us chances to breathe life into new bits of knowledge. More attention to economics tools which lead to a better market should be mixed with better welfare and should guarantee the equilibrium balance with profits and costs. Candeias and Morhard (2018).The sharing economy assists with accentuating how the agreeable practices as a 'pioneering opportunity' and aides in better "government assistance advancement". The
Corona Economy acquires Case Studies and reference for both the undergrad and the postgraduate schools of Business, Sociology and Law Students for a conversation on how Business Models are based on Cooperation and even Collaboration. Green (2011).

\subsubsection{Assemble stronger Communities}

As we are observing the rising effect of Coronavirus between 25th intently till 27th of February 2020, the updates on racial and strict pressures among Hindu and Muslims in India kept on coming as well. The breakout of (COVID-19) emergency indicated that we have to assemble secure networks more than anything if we endure more complex difficulties. The business continuity of both communities and business need to be tested again from different angles, including the interruption of the supply chain. Buheji(2020a). Selfishness versus Unity is a discussion that is going to more debate in the post coronavirus. For example, Pushing coronavirus cases outside the nation, or shutting the outskirts against a collusion nation are new practices that are going to influence the future socio-political relations as well. No government can guarantee or believe that it can have its 'comprehensive outskirt' any longer as the world is turning out to be one town. We have to continue building versatile networks that are comprehensive and interdisciplinary associated. Buheji(2018).

2.3.4. Re-Alignment for Understanding of Our Livelihood

This Corona Virus have moved our consideration and centre from being a riches looking for an animal to a higher amount of animal that esteem the significance and the estimation of personal satisfaction. While we were getting disconnected by the decision and concentrated on the 'benefit and misfortune's equation, we put some distance between the division of work and its way of thinking of advancement and riches creation. This leads the bend of free enterprise to forcefully drop down. World Bank (2014).How we are managing job in a capital-based economy today is driving us to dump our liabilities on the young and the group of people yet to come. 'Free-market 
economy' wrecking the monetary structure holding the system together.As capitalism based on the presumptions that an incredible a portion of the world's assets could be purchased, for example, terrains and characteristic assets could be brought paying little heed to who may be denied. At long last, in an entrepreneur economy, we have all the chance to make a big deal about ourselves. Cai, Y. (2017)

2.3.5. Restore the Original Capacity for Spiritual and Social Beings

We are Social creatures more than anything, and the frequency of the coronavirus settled on us acknowledge more the decision of being appended to God and reinforcing our otherworldliness. Likewise, the rate stirs us of the significance of rehearsing progressively public activity, or of being more socialbeing than just people being. Perhaps this is considerably gradually significant for the young ages who been contaminated with the flood of hello-tech and apply autonomy arrangements before being undermined by the coronavirus. The emergency aroused us on valuing the benefit of losing physical contact because of the dread of cross-sullying. The occurrence caused us to acknowledge the amount we love individuals around us and the genuine faithfulness for those we love. This mishap or episode assisted with disclosing how we have to adhere to the consistent improvement of our social foundations so it would affect the human activity in a comparative emergency later on. Esperandio, M. R. G.(2020)

Therefore, the (COVID-19) emergency would offer ascent to the significance of the social neuroscience is an interdisciplinary idea that could be dedicated to seeing how our bodies would be progressively fit to confront coming kind of complex emergency through re-reinforced social ties inside our environmental factors.

\section{METHODOLOGY}

Writing literature was directed to build up the decimation, noticeable and the shrouded chances that covid-19 outbreak, known scientifically as (COVID19) crisis brought to the world. In light of the combination of the writing, a future financial prescience was built up. The blend concentrated on the effect expected on the worldwide communities and how the post-corona virus would bolster the change for socio-financial matters that depend on independence and the inborn force. Also, an alert about the start of new trends in fashion, electronics manufacturing and services industry is proposed.

At long last, the combination from writing prompted literature review the future job and the ascent of epidemiology, followed by the type of viruses that are expected to come beyond the (COVID-19) crisis. This combination prompted the improvement of a system that could assist the world with developing a supported readiness for the alleviation of dangers and the advancement of chances that coronavirus, or whatever another future risk that should be looked by our species.

\section{RESULT}

\subsection{Introduction to the literature review:}

The consequences of the incorporated writing survey served to explain to a limited degree the future financial foreknowledge after coronavirus in 2020. Accordingly, the job of common urban areas amid an emergency, the sort of shopper devotion and responses are imagined. The creators remove that the following 20 to 30 a long time would the age of the move towards more reliance on inherent forces. Additionally, because of the test of crosscontaminations, according to the writing checked on, another pattern that influences a wide range of way of life industry may be activated. The distinguished research hole shows the ascent of the requirement for the study of disease transmission as the leading science, particularly with the improvement of past (COVID-19) infections. At that point, a system that improves our preparation for the following scourge danger would be proposed because of this engaging survey. 


\subsection{During breakout: Socio-Economic implementation} We've seen nothing like the COVID-19 pandemic, leaving us questions about how to adapt in these strange events. We know that this time is so horrible and isolating both personally and professionally, but still, we can improve the various things, find new opportunities underneath this breakout.We can focus on such things as:

\subsubsection{Business Planning for Future Growth:}

"The future depends on what we do in the present" MAHATMA GANDHI

While shoppers are investing more energy on the web, they're not quick to settle on choices about the future at present. On the off chance that you have the assistance that requires your clients to prepare or travel, your transformation rate will endure during the flare-up. So don't expect that a similar substance and promotions that acquired traffic before the pandemic will continue coming.

This can be a chance to draw in with your clients via web-based networking media and time to position the brand in the mind of consumers. It's time to shift marketing strategies(from the identification of a customer need to place the product) with during and post covid-19 breakout. We want to associate the things that are prevailing right now and use the substance (safety, hygienist, wash the hand, maintain social distance etc.) to deliver the product.

(i) For example, Chinese e-commerce giant fights COVID-19 by delivering essentials and spraying disinfectant.

E-commerce giant JD.com has delivered essential goods across China to fight the COVID-19 pandemic. The company, a Strategic Partner of the World Economic Forum, developed a drone route to Baiyang Lake in Hebei province. The route, which usually saw delivery of packages to the village by boat, was suspended due to the outbreak of the virus. With the drone program, the drones dropped parcels at a fixed point - so customers were able to collect them without human-to-human contact. (ii) For example, in regards to putting the mission first, Deloitte identified several crucial actions for leaders to take based on their analysis of the leading practices of multinational companies in other health crises. Launching and sustaining a crisis command centre, supporting talent and strategy, maintaining business continuity and financing, and staying engaged with customers are among the findings.

With the right approach, Deloitte believes the COVID-19 crisis can "become an opportunity for companies to create even more value and positive societal impact, rather than just bounce back to the status quo."

\subsubsection{Online events and offerings:}

Think about specific ways you can even now interface individuals from the comfort of home, including online classes, Facebook Live recordings and virtual gatherings utilizing apparatuses like google meet, cisco WebEx,Zoom. What's more, don't merely concentrate on coronavirus-related substance. Continue creating a video that will profit your venture marketing technique long after the COVID19 emergency is finished.

4.2.3 Develop the trust-based culture with the human resource:

The more worth you can offer your clients at present, the more fruitful you'll be as we move to another method of advertising and rise out of a worldwide emergency that made our reality significantly littler. A delighted employee ever delights the customer as well as company, and do a goal-directed behaviour always. No in this era, a company have to move engaging to sustain our human resource, While providing a changing environment (technology, the material, the way of doing work) knowledge.

For example: During this time, One of the largest public sector unit (PSU) of India, Bharat Heavy Electricals Limited (BHEL), the company has created more than 230 learning opportunities through various e-learning courses/webinars/trainings on technical, functional, managerial and behavioural domains for its employees. 


\subsection{Post breakout: Financial Future Foresight}

Coronavirus alarm exercises could figure out how to impact and build up our social orders and changed its conduct to think about future financial difficulties instead of mechanical devices and plans. This implies we can speed up the arrangements of future foreknowledge of business challenges.

When financial examples change, interests and power assets change alongside the organizational relations and what's more, the frameworks that help it. The foreknowledge that we are going to encounter greater insecurity, later on, requires us to reevaluate the modern relations and guarantee that they are adjusted by the comprehensive improvement that makes up for this hole.

\subsubsection{The new work paradigm:}

After the settlement from the emergency, we are relied upon to see new patterns beginning in style, hardware, innovation, administrations that guarantee or endeavour to act naturally supported against infections or relieve the effect of cross-contamination. Other designs would concentrate on the most proficient method to bring back humankind to its runway and keep it on the edge of specific progression. Be that as it may, new standards of financial matters would be the worry of numerous influencers, and the maxim of these pioneers would be.The quickly spreading Coronavirus has additionally incited innovation organizations to energize remote working for representatives, proclaiming another period later on for work. Large companies and private ventures the same were sufficiently agile to adjust to "telecommuting", during the beginning of the pandemic." In my view, remote working bears the tech segment a chance to reshape and reevaluate how associations can all the more likely put resources into their representatives. The deadly infection could, well, be a game-changer and move the story to grasp another work culture that is secured in a worldwide network.

A buzzword- work from home have been adding in the dictionary of organization. Many countries would have been implementing this category of work but who don't still apply, trying to achieve permanent.

"If you do not change according to the demand of time, then time will not give you a chance."

The system centre around improving the forces of surmising, which would assist us with resolving clashing data about human life-threatening dangers. The structure could trigger useful patterns that help new analysis or raise the accessibility of treatment at the correct time. Buheji (2019b). The most significant bit of leeway proposed by this system is that it could trigger higher interest cash from inside and cause us to ask "Why?" which lead to proactive investigation and sound activities dependent on essential circumstances. Buheji (2020b).

\section{DISCUSSION AND CONCLUSION}

No one knows how many people will be infected (or will pass away sadly), but it has caused the global stock markets to crash, which means as a business (or even a marketer), you will be affected.This (COVID19) emergency challenge things that cash can't purchase. Consequently, such an emergency is required to raise our emotions about our kindred people. For example, sentiments of the oppressed who can't get to numerous administrations while we are restricted due to the breakout as it were. For instance, the emergency raised our mindfulness about the sentiments of the jobless network individuals who by and large they experience mental discontent and an outlook that breeds feelings of disdain.As the speed of the virus of (COVID-19) and its throughput are escalating. As mentioned in the literature review, this is hitting the basis of the quality of life (QoL). This means we need to optimise solutions that eliminate this type of life development threatening and negative spillovers.The UNESCO is one of the leading players besides the WHO (for health and safety) and the World Bank (for financial stability) that could maintain the world calmness and confidence. The UNESCO has an essential role in maintaining the 
spread and delivery of education and humans learning programs.

Continuing the conveyance of this education, other than keeping the advancement of the edified combination and trade requires many thoroughly consider the container arrangements. China began the sensible ones, and the world started to follow, by actuating the e-learning in and gaining from far off projects. UNESCO (2020). In this way, it is enthusiastically suggested that UNESCO chiefs and all training heads from everywhere throughout the world adopt severe strategies towards recalculating the learning hours slightly the instruction establishment participation days as a technique for conveyance. Upgrade the procedures, what's more, methods for self and separation learning, other than stable structures for purposes of discovering that profit by troublesome instruction ideas. Christensen et al. (2008).

The world should be increasingly lithe but then hopeful about the importance and methods for taking care of the possible coming infectious pandemics. While this examination paper has been composed under crisis period since the beginning of the (COVID-19), where the epidemic isn't yet stopped, the specialists accept that the chance to support our barriers ought to be utilized. We should make a worldwide well-being hazard structure fit for ensuring human lives and vocations worldwide from the danger of such irresistible illness. The National

\section{Academies of Sciences Engineering Medication} (2016b). From this Paper we don't conclude the adverse effects, the comparative losses that the society, as well as globe, faced, we only find a hope which always hidden underneath of the unhoped, While we don't uncover it. The whole world faces this type of microorganism pandemic, but the earth is the only planet of creative species which meet the challenges and convert the loss into profit. And we just did. We have to respond to this pandemic with a positive vibe, with creating a new world, which full of integrity, creativeness, and growth and not with stagnation

\section{The final words:}

For the era beyond 2020, This paper and its system open bunches of ways for future investigations that are expected to fill the colossal hole of literature in the writing about complex critical thinking in managing emergencies of comparative nature and multifaceted nature as the (COVID-19).Due to the constraints of the scope of this research, Paper has some limitations. The Paper has not demonstrated the hazards hidden under the opportunities, what such risks would appear in the new business environment, how the dangers could be determined and how to mitigate such hazards. The creativity the creators bring to the information network in this work is that it brings up another system for managing drivers and attractors of change that emergencies and complex episodes bring along their raging waves. The Paper reflects how a rousing based economy mentality would take a gander at such degree of life challenges which came or yet to come.

\section{REFERENCES}

[1]. Albulescu, C. (2020). Coronavirus and oil price crash. Available at SSRN 3553452

[2]. Atkeson, A. (2020). What will be the economic impact of COVID-19 in the US? Rough estimates of disease scenarios (No. w26867). National Bureau of Economic Research.

[3]. Baldwin, R (2020), "Keeping the lights on: Economic medicine for a medical shock", VoxEU.org, 13 March.

[4]. Bogoch, I. I., Watts, A., Thomas-Bachli, A., Huber, C., Kraemer, M. U., \& Khan, K. (2020). Potential for global spread of a novel coronavirus from China. Journal of travel medicine, 27(2), taaa011.

[5]. Buheji, M (2018) Understanding the Power of Resilience Economy: An Inter-Disciplinary Perspective to Change the World Attitude to Socio-Economic Crisis, AuthorHouse, UK. 
[6]. Buheji, M (2019a) Enhancing Human Capacity. Curiosity as an Example, International Journal of Inspiration \& Resilience Economy 2019, 3(1): $0-0$.

[7]. Buheji, M (2019b) 'The Trust Project' Building better accessibility to Healthcare Services through Behavioural Economics and Inspiration Labs, International Journal of Economics, Commerce and Management, United Kingdom, 7(2): 526-535.

[8]. Buheji, M (2020a) 'Visualising Resilient Communities', Authorhouse Publishing, UK.

[9]. Buheji, M (2020b) Optimising the 'Economics of Curiosity' for Better Future Foresight. Tracking how Curiosity Can Solve Future SocioEconomic Challenges. American Journal of Economics, 10(1): 21-28.

[10]. Cai, Y. (2017). Effects of Active Site Inhibitors on APN-dependent Coronavirus Entry.

[11]. Candeias, V and Morhard, R (2018) The human costs of epidemics are going down but the economic costs are going up. Here's why. World Economic Forum. https://www.wefor um.org/agenda/2018/05/how-epidemics-infectthe-global-economy-and-what-to-do-about-it/. Accessed on: 1/2/2020.

[12]. Carlsson-Szlezak, P., Reeves, M., \& Swartz, P. (2020). What coronavirus could mean for the global economy. Harvard Business Review, 3.

[13]. Cheng, H. P., \& Yen, K. C. (2020). Does COVID-19 Affect the Financial Market?. Available at SSRN 3578263.

[14]. Christensen, C; Horn, M and Johnson, C (2008) Disrupting Class: How Disruptive Innovation Will Change the Way the World Learns. McGraw-Hill.

[15]. Coibion, O., Gorodnichenko, Y., \& Weber, M. (2020). Labor markets during the COVID-19 Crisis: A preliminary view (No. w27017). National Bureau of Economic Research.
[16]. Esperandio, M. R. G.(2020) Caring for the Mind is Caring for the Spirit: Spirituality and Health in times of Coronavirus COVID-19.

[17]. Green, J. (2011) Regimes of Social Cohesion: Societies and the Crisis of Globalization. Springer.

[18]. Helmich, R. C., \& Bloem, B. R. (2020). The impact of the COVID-19 pandemic on Parkinson's disease: Hidden sorrows and emerging opportunities. Journal of Parkinson's disease, 10(2), 351-354.

[19]. Henry Farrell and Abraham Newman(2020) Will the Coronavirus End Globalization as We Know It? Error! Hyperlink reference not valid. Accessed on:2 may, 2020 and updated on may 9, 2020.

[20]. Holmes, K. V. (2003). SARS coronavirus: a new challenge for prevention and therapy. The Journal of clinical investigation, 111(11), 16051609.

[21]. Kamradt-Scott, A., \& Lee, K. (2011). The 2011 pandemic influenza preparedness framework: global health secured or a missed opportunity? Political Studies, 59(4), 831-847.

[22]. Kim, S. and Liu, B. (2012) Are all crises opportunities? A comparison of how corporate and government organizations responded to the 2009 flu pandemic. Journal of Public Relations Research, 24(1), 69-85.

[23]. Li, J. B., Yang, A., Dou, K., \& Cheung, R. Y. (2020). Self-control moderates the association between perceived severity of the coronavirus disease 2019 (COVID-19) and mental health problems among the Chinese public.

[24]. Lora Jones, Daniele Palumbo \& David Brown(2020) Coronavirus: A visual guide to the economic impact https://www.bbc.com/news/business51706225,30 april.

[25]. Oxford Economics (2015) The Future of Chinese Travel, The Global Chinese Travel 
Market, A report by Oxford Economics for InterContinental Hotels Group.

[26]. susanfriesen (2020) How to Pivot Your Small Business Strategy During the COVID-19 Crisis https://evisionmedia.ca/how-pivot-smallbusiness-strategy-during-covid-19-crisis/

[27]. The National Academies of Sciences Engineering Medicine (2016a) Global Health Risk Framework. Resilient and Sustainable Health Systems to Respond to Global Infectious Disease Outbreaks: Workshop Summary. https://www.nap.ed u/catalog/21856/globalhealth-risk-framework-resilient-

andsustainable- health-systems-to. Accessed on: $1 / 2 / 2020$.

[28]. The National Academies of Sciences Engineering Medicine (2016b) The Neglected Dimension of Global Security. A Framework to Counter Infectious Disease Crises. The Commission on Global Health Risks and Framework for the Future. https://www.nap.edu/catalog/21854/globalhealth-risk-framework-governance-for-globalhealth-workshopsummary.https://www.ncbi.nlm.nih.gov/pubme d/27336117.Accessed on: 1/2/2020.

[29]. UNESCO (2020) How is China ensuring learning when classes are disrupted by coronavirus? Posted on 19/2/2020. https://en.unesco.org/news/how-chinaensuring-learning-wh en-classes-are-disruptedcoronavirus. Accessed on: 20/2/2020.

[30]. World Bank (2014) The economic impact of the 2014 Ebola epidemic: Short and medium term estimates for West Africa. Washington, DC: World Bank. http://documents.worldbank.org/curated/en/524 521468141287875/pdf/912190WP0see0a0 0070385314B00PUBLIC0.pdf. Accessed on: $1 / 2 / 2020$ and updated on $11 / 2 / 2020$.

[31]. World health organization (2020) Novel Coronavirus (2019-nCoV) SITUATION
REPORT-1https://www.who.int/docs/defaultsource/coronaviruse/situationreports/20200121-sitrep-1-2019ncov.pdf?sfvrsn=20a99c104. Accessed on: 25 march, 2020.

\section{Cite this article as :}

Dr. Ranjana Kanungo, Deepak K. Nama, " The Covid19 vs Globe : Turn Disaster Into Opportunity", International Journal of Scientific Research in Science and Technology(IJSRST), Print ISSN : 2395-6011, Online ISSN : 2395-602X,Volume 8, Issue 3, pp.70-81, May-June-2021. Available at doi : https://doi.org/10.32628/IJSRST218321 Journal URL : https://ijsrst.com/IJSRST218321 